\title{
Perancangan Fasilitas Gudang Dalam Sistem Logistik (Pendekatan Berbasis Laboratorium)
}

Nanda Ruswandi ${ }^{\text {a, },{ }^{*} \text {, Iwan Sukarno }}{ }^{\text {b,2 }}$, Harummi Sekar Amarilies ${ }^{\text {b, }}$, Rachmad Inca Liperda ${ }^{b, 4}$, M. Welano Kharisma ${ }^{\mathrm{b}, 5}$, Mega Rizkah Sudiar ${ }^{\mathrm{b}, 6}$, Raina Fridayanti ${ }^{\mathrm{b}, 7}$

1,2,3,4,5,6,7 Teknik Logistik, Universitas Pertamina, Indonesia

${ }^{1}$ nandaruswandi.industri@gmail.com *

\section{ARTICLE INFO}

\section{Article history}

Received 2020-10-03

Revised 2020-10-08

Accepted 2020-10-31

Keywords

Maintenance

Lubricants

Logistics Facility

Third Party Logistics (3PL)

\begin{abstract}
All of automotive companies around the world are aggressively producing large number of motorized vehicles, especially cars. A car is a transportation mode that is widely used by the middle and upper class. The large number of cars uses cannot be separated from the needs for maintenance of the vehicle itself. Lubricant is the core of engine maintenance on vehicles. Therefore, the demand for lubricants continues to increase due to the increasing demand for cars. Bandar Lampung, for the example, is increasing in the term of the city's population that is affecting its number of people who own cars. This phenomenon caused the demand for lubricants to increase significantly, so that many lubricant distributors were overwhelmed by this demand. Seeing this opportunity, the RWM Logistics, which is a new Third Party Logistics (3PL) company with value added service is lubricant packaging, has a plan to build a lubricant storage facility in Bandar Lampung. In designing the facility, the company has to decide the layout design, area requirements, material handling planning, and the operational costs. The development of this facility is expected to help the company to meet the demand of lubricant products that were not covered by other distributors.
\end{abstract}

\section{A. PENDAHULUAN}

Dunia industri otomotif di dunia sedang gencarnya memproduksi kendaraan bermotor, khususnya mobil. Ketika memiliki kendaraan, tentunya diperlukan pemeliharaan kepada mesin kendaraan agar umur ekonomis pemakaian kendaraan lebih panjang. Pelumas atau oli sangat berperan penting dalam perawatan mesin kendaraan. Peningkatan permintaan akan kebutuhan mobil juga mempengaruhi adanya fluktuasi pada permintaan pelumas. Hal ini terjadi pada wilayah Kota Bandar Lampung yang populasi penduduknya mengalami peningkatan. Namun, permintaan akan pelumas tersebut tidak dapat dipenuhi secara menyeluruh dikarenakan minimnya penyedia oli di Kota Bandar Lampung. Dalam hal ini, perusahaan RWM Logistics yang merupakan perusahaan baru dalam bidang Jasa Penyedia Layanan Logistik (3PL) dengan value added service berupa pengemasan oli, berencana untuk membangun sebuah fasilitas penyimpanan oli di Kota Bandar Lampung agar permintaan akan oli mobil dapat terpenuhi.

Sebelum membangun suatu fasilitas baru, tentunya diperlukan perencanaan serta perancangan fasilitas yang matang agar tujuan yang telah ditentukan perusahaan dapat tercapai. Hal tersebut perlu dilakukan mengingat pentingnya fungsi dari fasilitas sebagai sarana dan prasarana penunjang proses bisnis perusahaan. Perencanaan yang harus dipersiapkan mulai dari business strategic plan, dengan menganalisis apa saja kekuatan dan kelemahan perusahaan serta peluang yang dimiliki dan ancaman yang mungkin akan dihadapi oleh perusahaan. Perencanaan strategi terhadap kompetitor di bidang yang sama juga perlu dilakukan agar perusahaan dapat bertahan serta bersaing dengan kompetitif. 
Perancangan fasilitas perlu memperhatikan beberapa aspek penting, salah satunya adalah perencanaan kebutuhan area dan tata letak fasilitas. Menurut Russel dan Taylor, perencanaan tata letak adalah untuk meminimalkan ongkos alat penanganan material, meningkatkan efisiensi penggunaan ruang dan tenaga kerja, mengurangi kendala selama aktivitas, serta mempermudah komunikasi di dalam fasilitas. Aspek lain yang tidak kalah penting seperti perencanaan alat penanganan material, penentuan ukuran lot kebutuhan material, perencanaan kebutuhan pekerja, serta perhitungan biaya operasional perusahaan. Demi mencapai tujuan perusahaan, maka pada penelitian ini akan dijabarkan perencanaan paling optimal dengan mempertimbangkan berbagai aspek tersebut dalam melakukan perancangan fasilitas untuk pengemasan, penyimpanan, dan distribusi oli mobil di wilayah Kota Bandar Lampung milik perusahaan RWM Logistics.

Penelitian mengenai perancangan fasilitas gudang produk oli mobil di wilayah Kota Bandar Lampung merupakan penyelesaian kasus yang digunakan dalam modul praktikum Perancangan Fasilitas Logistik. Praktikum yang diguanakn dalam penelitian ini sendiri memiliki empat sub modul, yaitu Perencanaan Kapasitas, Lokasi dan Kebutuhan Material, Pemilihan Peralatan Penanganan Material dan Kebutuhan Operator Lini Produksi, Perencanaan Gudang, serta Perencanaan Tata Letak Gudang dan Biaya Operasional. Perancangan fasilitas dilakukan secara bertahap sesuai dengan sub modul yang dimulai dengan menentukan kapasitas produksi dari fasilitas yang akan dibangun hingga menentukan tata letak dan biaya operasional fasilitas sebagai tahap akhir perancangan fasilitas yang akan dibangun.

\section{B. METODE PENELITIAN}

Penelitian ini dilakukan dengan berlandaskan beberapa teori relevan yang digunakan untuk membantu proses perumusan masalah, pengolahan data, pengambilan kesimpulan dan solusi yang akan diterapkan.

\section{Analisis Strengths, Weaknesses, Opportunities, and Threats (SWOT) dan Analisis Kompetitor}

Analisis SWOT merupakan teknik yang digunakan untuk mengetahui kekuatan dan kelemahan suatu organisasi, serta digunakan untuk mengidentifikasi kesempatan dan ancaman yang mungkin dihadapi dari kompetitor. Keunggulan yang didapatkan dengan menggunakan SWOT analysis antara lain:

a. Fokus kepada kekuatan yang dimiliki, meminimalisir kelemahan dan ancaman, memanfaatkan kesempatan sebaik mungkin.

b. Membantu dalam menentukan tujuan perusahaan dan langkah-langkah untuk mencapainya.

c. Membantu perusahaan untuk keep-in-track dan berpedoman pada visi misi perusahaan.

\section{Perencanaan Gudang}

Dalam merencanakan fasilitas pabrik, di dalamnya perlu ditentukan pola aliran material yang bertujuan untuk mengoptimalkan setiap kegiatan di dalam warehouse dan memaksimalkan produktivitas. Dikenal beberapa jenis pola aliran material yang umum digunakan, yaitu:
a. U-shaped Model
b. I-shaped Model
c. L-shaped Model

\section{Perencanaan Material Handling Equipment (MHE)}

Material handling adalah suatu fungsi yang vital dalam industri manufaktur dan distribusi karena menghubungkan sistem yang ada. Pada pemilihan MHE digunakan prinsip-prinsip material handling untuk menentukan MHE, antara lain planning, standardization, work, ergonomic, unit load, space utilization, system, automation, environmental, dan life cycle cost. Selain prinsip tersebut, perlu diketahui tipe-tipe MHE yang umum digunakan guna memastikan pemilihan alat sesuai kebutuhan. MHE yang biasa digunakan dalam industri antara lain industrial trucks, cranes, dan conveyor. 


\section{Penentuan Lot Pemesanan dalam Gudang}

Proses pengadaan material tersebut dapat dilakukan dengan dua acara, yaitu dengan memproduksi material yang digunakan (MFG) atau membeli material (BO). Dalam merencanakan pemesanan kembali, dilakukan penentuan ukuran lot pemesanan yang dapat dilakukan dengan beberapa metode, antara lain:

a. Lot-for-Lot (LFL)

Metode LFL dilakukan dengan memesan sesuai jumlah kebutuhan di setiap periodenya, sehingga tidak menghasilkan ongkos simpan yang tinggi. LFL biasa digunakan untuk item mahal atau memiliki tingkat diskontinuitas permintaan yang tinggi.

b. Economic Order Quantity (EOQ)

Model EOQ mendeskripsikan pentingnya trade-off antara ongkos pesan dan ongkos simpan.

c. The Silver-Meal Heuristic

Metode Silver-Meal adalah metode heuristik yang dilakukan dengan menentukan rata-rata biaya yang dikeluarkan per periode. Perhitungan akan berhenti jika biaya yang dihitung mengalami kenaikan.

d. Least Unit Cost (LUC)

Pada metode LUC dilakukan penentuan biaya berdasarkan jumlah periode pemesanan. Horizon pemesanan yang memiliki biaya paling minimum dipilih sebagai ukuran pemesanan.

\section{Perencanaan Kebutuhan Area Penunjang}

Menentukan kebutuhan area penunjang dapat dilakukan dengan beberapa pendekatan, yaitu dengan memperhatikan data histori atau dengan mengalokasikan ruang yang sesuai untuk setiap area. Beberapa area penunjang yang perlu dirancang antara lain:

a. Office Area, luasannya dipengaruhi oleh banyaknya personel dan fasilitas di dalamnya.

b. Area penunjang gudang, meliputi area yang diperlukan untuk menunjang kegiatan gudang, seperti charging station dan APAR.

c. Area penunjang kantor, memiliki fungsi yang kurang lebih sama seperti area penunjang gudang.

\section{Perencanaan Kebutuhan SDM}

Dalam merencanakan pendirian suatu fasilitas, perlu dilakukan perencanaan kebutuhan personel. Penentuan personel adalah penentuan jumlah dan spesifikasi manusia yang dibutuhkan untuk melaksanakan suatu tugas atau fungsi di dalam suatu organisasi dalam rangka mencapai tujuan. Dalam menentukan kebutuhan personel, langkah-langkah yang perlu dilakukan adalah sebagai berikut.

a. Analisis Pekerjaan

Analisis pekerjaan adalah proses pengumpulan atau pengelompokan aktivitas pekerjaan serta kualifikasi yang dibutuhkan. Keluaran yang didapatkan antara lain deskripsi pekerjaan dan spesifikasi pekerjaan.

b. Penentuan Kebutuhan

Pada proses ini dilakukan analisis terhadap jumlah personel yang ada serta kesesuaiannya dengan kebutuhan organisasi. Analisis ini perlu dilakukan untuk mengetahui apakah perlu dilakukan penambahan atau pengurangan personel.

\section{Perhitungan Biaya Operasional Fasilitas}

Biaya operasional merupakan biaya yang dikeluarkan untuk melakukan seluruh aktivitas di dalam suatu fasilitas. Di dalam gudang, biaya operasional yang perlu dikeluarkan antara lain:

a. Biaya perpindahan alat penanganan material berkaitan dengan proses perpindahan barang dan alat penanganan material yang digunakan. 
b. Biaya konsumsi energi dengan input besar kebutuhan energi yang dibutuhkan selama waktu proses.

c. Biaya tenaga kerja langsung, dalam hal ini adalah upah operator mesin maupun non-mesin.

\section{HASIL DAN PEMBAHASAN}

\section{Analisis SWOT dan Competitor}

Untuk meningkatkan market share, peneliti mengidentifikasi beberapa pesaing yang ada di Kota Bandar Lampung. Berdasarkan hasil penelusuran, ditemukan ada 3 kompetitor yang bergerak dalam bidang yang sama. Market share terbanyak atau pada level superior dipegang oleh PT. Surya Serba Mulia karena perusahaan tersebut telah berdiri sejak tahun 1998 dan memiliki market share sebesar 64\%. Perusahaan ini telah bekerjasama dengan perusahaan besar, seperti PT. Pertamina Lubricants dalam memasok oli di daerah Lampung. Selain Pertamina, ditemukan juga perusahaan lainnya yang dilayani oleh perusahaan ini dalam hal packaging dan distribusi. Perusahaan ini telah banyak mendapatkan penghargaan salah satunya adalah Best Sales Pelumas Pertamina berturut-turut tahun 2004 dan 2005. Kemudian perusahaan yang berada pada same level adalah PT. Sumber Bumi Pratama dengan market share sebesar 15,8\%. Perusahaan ini berdiri sejak tahun 1996 dan melayani jasa packaging dan distribusi oli sejak tahun 1972. Perusahaan ini tidak hanya melayani jasa packaging dalam bentuk botol, tetapi juga dalam bentuk kaleng. Lalu, terakhir adalah perusahaan yang berada pada level inferior, yaitu PT. Sinta Sejahtera Lestari dengan market share sebesar 6\%. Perusahaan ini juga bekerjasama dengan PT. Pertamina Lubricants untuk jasa packaging dan distribusi oli. Namun perusahaan ini tergolong baru, sehingga belum memiliki market share yang tinggi. Oleh karena itu, kami menyusun strategi untuk meningkatkan market share peneliti yang saat ini hanya sebesar $14.2 \%$ dengan mengambil alih market share perusahaan inferior. Berikut analisis SWOT untuk mendapatkan strategi yang dapat diterapkan di perusahaan ini.

a. The Input Stage

Berikut adalah tabel penentuan untuk External Factor Evaluation (EFE) matrix dan Internal Factor Evaluation (IFE) matrix.

Tabel 1. Internal Fact

\begin{tabular}{llcc}
\hline \multicolumn{1}{c}{ Key Internal Factors } & Weight & Rating & $\begin{array}{c}\text { Weighted } \\
\text { Score }\end{array}$ \\
\hline a) Strengths & & & 0.4 \\
1. Harga lebih bersaing & 0.1 & 4 & 0.15 \\
2. Menggunakan green technology & 0.05 & 3 & 0.4 \\
3. Pegawai yang memiliki keahlian dibidangnya & 0.1 & 4 & 0.2 \\
4. Mampu memenuhi semua kebutuhan konsumen & 0.05 & 4 & 0.3 \\
5. Mempunyai banyak distribution center & 0.1 & 3 & 0.5 \\
Weaknesses & & & 0.3 \\
1. Perusahaan baru & 0.25 & 2 & 0.06 \\
2. Belum mempunyai pangsa pasar yang luas & 0.15 & 2 & 0.14 \\
3. Birokrasi yang belum sempurna & 0.06 & 1 & 0.07 \\
4. Masih memiliki sedikit armada transportasi & 0.07 & 2 & 2.52 \\
5. Belum mengetahui dengan pasti karakteristik yang & 0.07 & 1 & \\
$\quad$ diinginkan konsumen & & & \\
\hline
\end{tabular}


Tabel 2. External Fact

\begin{tabular}{lccc}
\hline \multicolumn{1}{c}{ Key External Factors } & Weight & Rating & $\begin{array}{c}\text { Weighted } \\
\text { Score }\end{array}$ \\
\hline a) Opportunities & & & 0.6 \\
1. Peningkatan jumlah mobil setiap waktu & 0.2 & 3 & 0.3 \\
2. Biaya karyawan murah & 0.1 & 3 & 0.1 \\
3. Meningkatkan akses ke seluruh kota & 0.05 & 2 & 0.1 \\
4. Pajak yang murah & 0.05 & 2 & 0.6 \\
5. Dekat dengan pelabuhan & 0.2 & 3 & 0.6 \\
Threats & & & 0.14 \\
1. Market share yang masih rendah & 0.2 & 3 & 0.1 \\
2. Loyalitas pelanggan terhadap perusahaan lama & 0.07 & 2 & 0.03 \\
3. Monopoli pasar oleh kompetitor & 0.05 & 2 & 0.1 \\
4. Permintaan konsumen yang berbeda-beda & 0.03 & 1 & 2.67 \\
5. Kebijakan pemerintah tentang produk ramah & 0.05 & 2 & \\
\hline
\end{tabular}

\section{b. The Matching Stage}

Strategi yang dihasilkan pada matriks SWOT secara garis bersar menghasilkan empat jenis strategi, yakni Strengths-Opportunities (SO) Strategies, Weaknesses-Opportunities (WO) Strategies, Strengths-Threats (ST) Strategies, dan Weaknesses-Threats (WT) Strategies. SO-strategies menggabungkan kelebihan perusahaan dengan kesempatan yang dimiliki untuk menghasilkan suatu strategi, WO-strategies bertujuan meminimalisir kekurangan perusahaan menggunakan kesempatan yang ada, ST-strategies bertujuan meminimalisir ancaman dengan mengoptimalkan kelebihan perusahaan, dan WT-strategies bertujuan menghasilkan strategi yang dapat mengatasi kekurangan serta ancaman pada perusahaan. Berikut adalah matriks SWOT kami berdasarkan data pada penggabungan tabel external factor evaluation (EFE) matrix dan internal factor evaluation (IFE) matrix yang telah dilakukan pada tahap sebelumnya.

Tabel 3. Strengths-Weaknesses-Opportunities-Threats (SWOT) Matrix

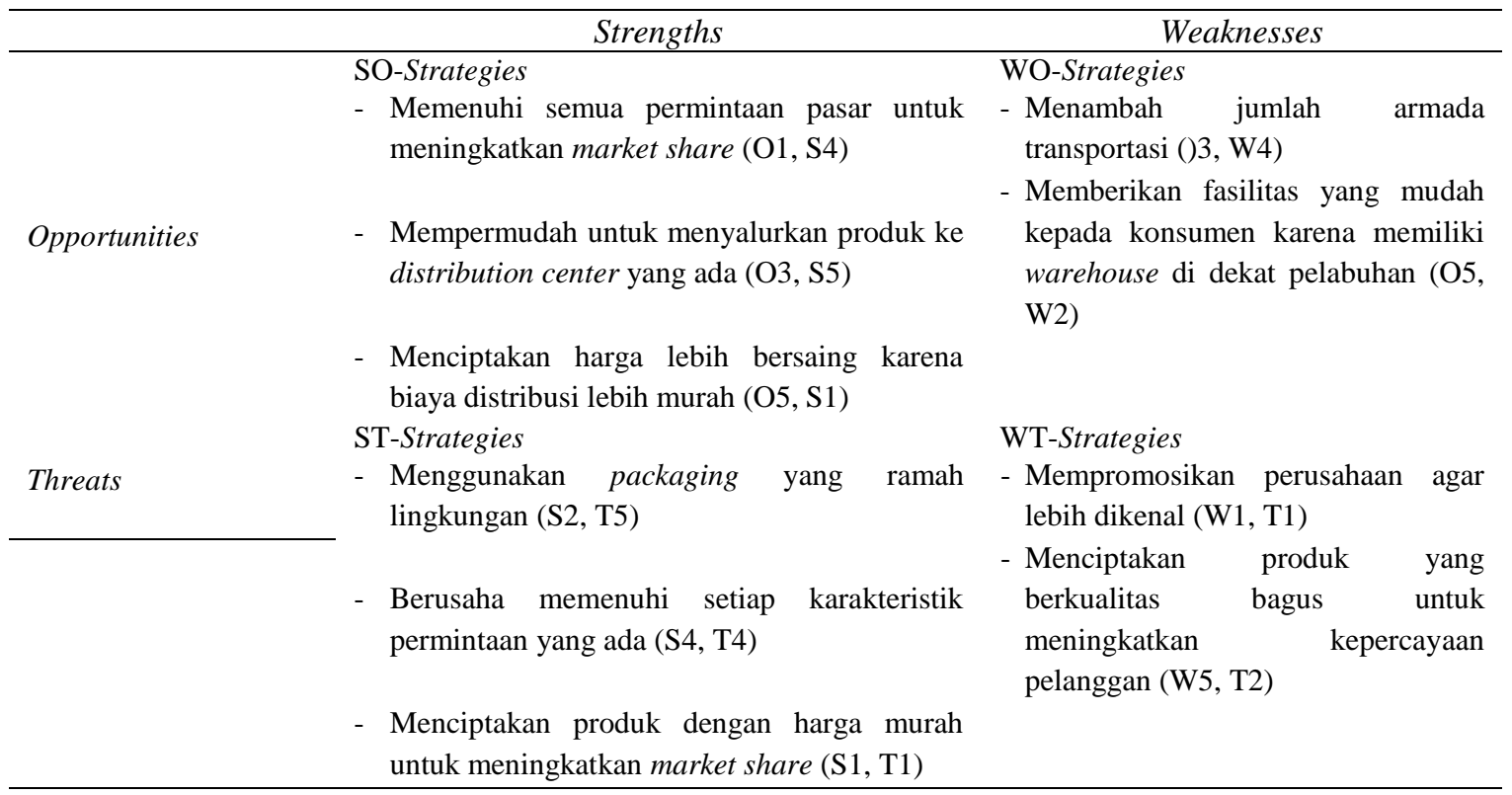

Berdasarkan matriks SWOT yang telah disusun pada Tabel 3, dihasilkan beberapa strategi yang dapat diterapkan oleh perusahaan. Salah satu contoh strategi yang dihasilkan adalah SO-strategies dengan strategi memenuhi semua permintaan pasar untuk meningkatkan 
market share perusahaan. Strategi ini sendiri menggabungkan opportunity pertama pada external fact dengan strength kelima pada internal fact. Seiring dengan kesempatan yang terbuka karena jumlah mobil yang terus meningkat setiap tahunnya, menyebabkan kebutuhan akan produk pelumas juga akan terus meningkat. Dengan demikian, perusahaan dapat mengoptimalkan distribution center yang dimiliki untuk dapat memenuhi semua permintaan pasar dalam rangka meningkatkan market share perusahaan.

\section{c. The Decision Stage}

\section{SWOT Analysis Diagram}

Sebelum membuat diagram analisis SWOT, kita harus menghitung nilai untuk setiap komponen dalam tabel EFE matrix dan IFE matrix. Perhitungan nilai untuk setiap komponen tersebut dapat dilakukan dengan cara sebagai berikut.

Nilai dari sumbu X:

$\mathrm{S}-\mathrm{W}=$ Total nilai strengths pada matriks - total nilai weaknesses pada matriks

$$
\begin{aligned}
& =(0.4+0.15+0.4+0.2+0.3)-(0.5+0.3+0.06+0.14+0.07) \\
& =0.38
\end{aligned}
$$

Nilai dari sumbu Y:

$\mathrm{O}-\mathrm{T}=$ Total nilai opportunities pada matriks - total nilai threats pada matriks

$$
\begin{aligned}
& =(0.6+0.3+0.1+0.1+0.6)-(0.6+0.14+0.1+0.03+0.1) \\
& =0.73
\end{aligned}
$$

Berdasarkan hasil perhitungan, diagram analisis SWOT dapat dilihat pada Gambar 1.

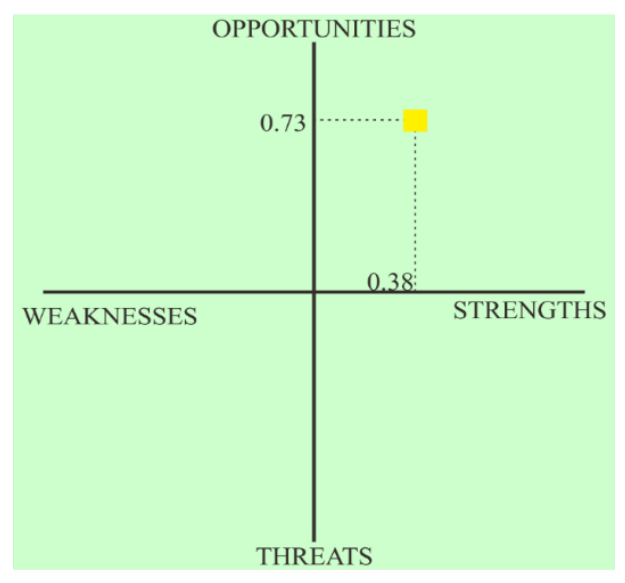

Gambar 1. Diagram Analisis SWOT

\section{Chosen Alternative Strategies}

Berdasarkan diagram analisis SWOT seperti pada Gambar 1, kuadran 1 adalah pilihan terbaik. Strategi yang terpilih adalah SO-Strategies sebagai berikut.

a. Memenuhi semua permintaan pasar untuk meningkatkan market share.

b. Mempermudah untuk menyalurkan produk ke distribution center yang ada.

c. Menciptakan harga lebih bersaing karena biaya ditribusi lebih murah.

\section{Analisis Material Flow}

Pada layout usulan di awal perencanaan fasilitas, pola aliran material yang dipilih adalah pola aliran material berbentuk I. Namun dikarenakan adanya penyesuaian dengan layout keseluruhan fasilitas, maka diputuskan untuk mengubah pola menjadi berbentuk U. Pola ini 
dinilai lebih optimal dan sesuai jika diaplikasikan pada gudang perusahaan. Selain itu, pola aliran material berbentuk $U$ juga dapat memaksimalkan penggunaan docks dan dapat meminimumkan pergerakan barang. Penggunaan ruang di fasilitas pun dapat dimaksimalkan.

Aktivitas di dalam gudang dimulai sejak material, baik itu bahan baku maupun barang bought out (BO), masuk ke gudang melalui area receiving. Selanjutnya material akan diproses menjadi kemasan botol pelumas mobil ukuran 4 liter yang siap didistribusikan ke seluruh konsumen RWM Logistics di kota Lampung. Proses pengemasan pelumas dilakukan dengan bantuan beberapa mesin, yaitu mesin filling, mesin pengemasan, dan mesin palletizing. Ketiga mesin utama tersebut dihubungkan dengan conveyor belt. Selain itu, proses pemindahan produk di luar area produksi dilakukan menggunakan forklift.

\section{Analisis Perencanaan Material Handling Equipment}

Material handling equipment yang digunakan haruslah sesuai dengan kebutuhan gudang maupun area produksi. Dalam menentukan MHE, terlebih dahulu ditentukan material yang akan dipindahkan, dalam hal ini adalah tumpukan kardus di atas pallet yang berisi oli. Selanjutnya, dihitung kapasitas pallet yang akan dipindahkan, agar diketahui kapasitas MHE yang diinginkan.

Berdasarkan perhitungan yang telah dilakukan, total volume dan berat pallet yang diangkut adalah $1.256 .160 \mathrm{~cm}^{3}$ dan $1.088 \mathrm{~kg}$. Berdasarkan informasi tersebut, forklift yang memenuhi spesifikasi yang dibutuhkan memiliki spesifikasi sebagai berikut.

Model

Power Type

Kapasitas Loading

Kapasitas Volume

Turning Radius

Max. lifting height

Fork Size

Dimensi

Kecepatan
: FPRT-20s0

: Deep Cycle Traction Battery

: $2000 \mathrm{~kg}$

: $1.920 .000 \mathrm{~cm}^{3}$

: $2825 \mathrm{~mm}$

: $7500 \mathrm{~mm}$

: $(920 \times 100 \times 35) \mathrm{mm}$

: (1802x1240) $\mathrm{mm}$

: $10.2 \mathrm{~km} / \mathrm{h}$

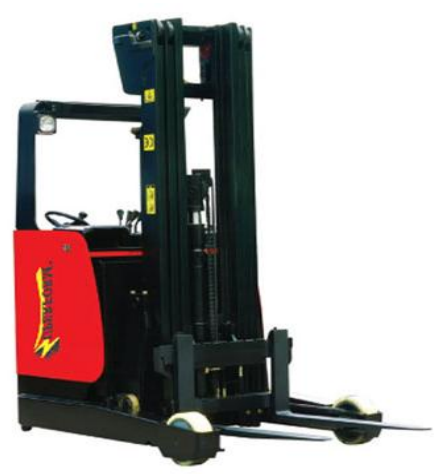

Gambar 2. Material Handling Equipment

Sumber: http://banngai.co.id

\section{Analisis Penentuan Ukuran Lot Pemesanan untuk Kebutuhan Bahan Baku}

Kebutuhan bahan baku berupa oli yang dikirim dalam bentuk bulk menggunakan truk tangki. Penentuan besar lot pemesanan kebutuhan bahan baku dilakukan untuk mengetahui 
jumlah pemesanan yang optimal serta waktu yang tepat untuk melakukan pemesanan. Berikut adalah ringkasan perhitungan besar lot pemesanan kebutuhan bahan baku.

Tabel 4. Ukuran Lot Pemesanan Bahan Baku

\begin{tabular}{cccccccc}
\hline $\begin{array}{c}\text { Biaya Pesan } \\
\text { (Rp/Order) }\end{array}$ & $\begin{array}{c}\text { Biaya Simpan } \\
\text { (Rp/liter/hari) }\end{array}$ & $\begin{array}{c}\text { Demand } \\
\text { (botol/minggu) }\end{array}$ & $\begin{array}{c}\text { Total } \\
\text { Demand } \\
\text { (botol/bulan) }\end{array}$ & $\begin{array}{c}\text { EOQ } \\
\text { (botol) }\end{array}$ & $\begin{array}{c}\text { Kedatangan } \\
\text { Truk Tiap } \\
\text { Sekali Pesan } \\
\text { (unit) }\end{array}$ & Frekuensi & $\begin{array}{c}\text { Periode } \\
\text { Pemesanan }\end{array}$ \\
\hline 300000 & 20 & 88367 & 371808 & 22517 & 6 & 17 & 1 \\
\hline
\end{tabular}

\section{Analisis Penentuan Ukuran Lot Pemesanan untuk Kebutuhan Barang BO}

Kebutuhan barang BO, seperti botol, tutup botol, plastic wrap, dan kardus dikirim dalam bentuk bulk menggunakan 2 jenis truk kontainer berukuran besar dan kecil. Penentuan besar lot pemesanan kebutuhan barang BO dilakukan untuk mengetahui jumlah pemesanan yang optimal serta waktu yang tepat untuk melakukan pemesanan kebutuhan barang BO. Unitisasi bulk untuk kebutuhan barang BO adalah per pallet, karena barang datang dari supplier dalam kondisi sudah dipaletisasi. Berikut adalah ringkasan perhitungan besar lot pemesanan kebutuhan barang BO.

Tabel 5. Ukuran Lot Pemesanan Barang BO

\begin{tabular}{ccccccccccccc}
\hline No & $\begin{array}{c}\text { Nama } \\
\text { Barang }\end{array}$ & $\begin{array}{c}\text { Dimensi Barang }(\mathrm{m}) \\
\mathrm{p}\end{array}$ & $\mathrm{l}$ & $\mathrm{t}$ & $\begin{array}{c}\text { Ongkos } \\
\text { Pesan } \\
\text { (Rp/order) }\end{array}$ & $\begin{array}{c}\text { Ongkos } \\
\text { Simpan } \\
\text { (Rp/order) }\end{array}$ & $\begin{array}{c}\text { Demand } \\
\text { (bulan) }\end{array}$ & $\begin{array}{c}\text { Isi/bulk } \\
\text { (Remand } \\
\text { (bulk) }\end{array}$ & $\begin{array}{c}\text { EOQ } \\
\text { (botol) }\end{array}$ & $\begin{array}{c}\text { Frekuensi } \\
\text { Pesan }\end{array}$ & $\begin{array}{c}\text { Periode } \\
\text { Pesan }\end{array}$ \\
\hline 1 & Botol & 0.32 & 0.06 & 0.24 & 250000 & 1350 & 371808 & 270 & 1378 & 153 & 10 & 2 \\
2 & $\begin{array}{c}\text { Tutup } \\
\text { Botol }\end{array}$ & 0.045 & 0.045 & 0.045 & 250000 & 63000 & 371808 & 12600 & 30 & 4 & 8 & 2 \\
3 & $\begin{array}{c}\text { Plastik } \\
\text { Wrap }\end{array}$ & 1000 & 0.03 & 1.4 & 250000 & 20 & 30 & 4 & 8 & 1 & 8 & 2 \\
4 & Kardus & 0.32 & 0.36 & 0.24 & 250000 & 1400 & 61968 & 280 & 222 & 61 & 4 & 5 \\
\hline
\end{tabular}

\section{Analisis Perencanaan Kebutuhan Pekerja}

\section{a. Operator Mesin}

Operator mesin ditentukan berdasarkan jumlah mesin utama yang digunakan pada lini produksi. Adapun rincian jumlah operator yang diperlukan oleh perusahaan RWM Logistics dapat dilihat pada tabel di bawah ini.

Tabel 6. Kebutuhan Operator Mesin

\begin{tabular}{ccccc}
\hline No & Nama Mesin & $\begin{array}{c}\text { Kebutuhan } \\
\text { Operator/Mesin }\end{array}$ & $\begin{array}{c}\text { Jumlah Mesin } \\
\text { Aktual }\end{array}$ & $\begin{array}{c}\text { Total } \\
\text { Operator }\end{array}$ \\
\hline 1 & Mesin Filling & 1 & 1 & 1 \\
2 & Mesin Pengemasan & 1 & 2 & 1 \\
3 & Mesin Palletizing & 1 & 2 & 1 \\
\hline
\end{tabular}

\section{b. Operator Non-Mesin}

Operator non-mesin ditentukan berdasarkan jumlah kebutuhan pekerja untuk setiap aktivitas pergudangan. Adapun rincian jumlah operator yang diperlukan oleh perusahaan RWM Logistics dapat dilihat pada tabel di bawah ini.

Tabel 7. Kebutuhan Operator Non-Mesin 


\begin{tabular}{ccc}
\hline No & Nama Aktivitas & Kebutuhan Operator/Aktivitas \\
\hline 1 & Receiving & 1 \\
2 & Shipping & 1 \\
3 & Ground Handling & 4 \\
4 & Quality Control & 2 \\
\hline
\end{tabular}

\section{c. Operator Alat Material Handling}

Operator alat material handling ditentukan berdasarkan jumlah alat material handling yang digunakan. Adapun rincian jumlah operator yang diperlukan oleh perusahaan RWM Logistics dapat dilihat pada tabel di bawah ini.

Tabel 8. Kebutuhan Operator Alat Material Handling

\begin{tabular}{|c|c|c|c|c|c|c|c|}
\hline No & Asal & Tujuan & $\begin{array}{c}\text { Nama } \\
\text { Material } \\
\text { Handling }\end{array}$ & $\begin{array}{c}\text { Frekuensi } \\
\text { Perpindahan }\end{array}$ & $\begin{array}{c}\text { Jumlah } \\
\text { Material } \\
\text { Handling }\end{array}$ & $\begin{array}{c}\text { Kebutuhan } \\
\text { Operator }\end{array}$ & $\begin{array}{c}\text { Total } \\
\text { Operator }\end{array}$ \\
\hline 1 & $\begin{array}{c}\text { Area } \\
\text { Receiving }\end{array}$ & $\begin{array}{c}\text { Gudang } \\
\text { Penyimpanan } \\
\text { Barang BO }\end{array}$ & Forklift & 160 & 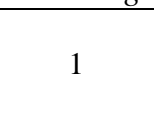 & 1 & 1 \\
\hline 2 & $\begin{array}{l}\text { Production } \\
\text { Line }\end{array}$ & $\begin{array}{c}\text { Gudang } \\
\text { Penyimpanan } \\
\text { Finished Goods }\end{array}$ & Forklift & 62 & 1 & 1 & 1 \\
\hline 3 & $\begin{array}{l}\text { Gudang } \\
\text { Penyimpanan } \\
\text { Finished } \\
\text { Goods }\end{array}$ & Shipping & Forklift & 784 & 4 & 1 & 4 \\
\hline
\end{tabular}

\section{d. Personel Kantor}

Personel kantor bertugas untuk menjalankan fungsi-fungsi sesuai dengan job description yang telah ditentukan agar perusahaan dapat bekerja dengan sebagaimana mestinya. Adapun rincian jumlah personel kantor yang diperlukan oleh perusahaan RWM Logistics dapat dilihat pada tabel di bawah ini.

Tabel 9. Kebutuhan Personel Kantor

\begin{tabular}{ccc}
\hline No & Nama Jabatan & Jumlah Personil \\
\hline 1 & Kepala Gudang & 1 \\
2 & Kepala Bidang Administrasi & 1 \\
3 & Manajer Produksi & 1 \\
4 & Manajer Distribusi & 1 \\
5 & Manajemen Penanganan Material dan Peralatan & 1 \\
6 & Manajer Pengadaan & 1 \\
7 & Manajer Pemeliharaan dan Penjaminan Mutu & 1 \\
8 & Staf Administrasi & 2 \\
9 & Staf Perencanaan Produksi & 1 \\
10 & Staf Pengadaan & 1 \\
11 & Staf Maintenance & 1 \\
12 & Staf IT & 1 \\
13 & Staf HSE & 1 \\
14 & Cleaning Service & 4 \\
\hline
\end{tabular}

\section{Analisis Perhitungan Biaya Operasional}

\section{a. Biaya Perpindahan}

Menghitung biaya perpindahan material handling perlu dilakukan untuk mengetahui biaya operasional yang dikeluarkan oleh perusahaan. Untuk mengetahui biaya perpindahan yang dikeluarkan oleh material handling pada saat memindahkan material diperlukan beberapa data, yaitu jarak perpindahan material handling dari titik asalnya ke titik tujuan dan frekuensi perpindahan. Selain itu, diperlukan pula data Ongkos Material Handling $(\mathrm{OMH})$ untuk menghitung biaya perpindahan material handling. Biaya perpindahan alat 
penanganan material yang digunakan oleh RWM Logistics dapat dilihat pada tabel di bawah ini.

Tabel 10. Perhitungan Biaya Perpindahan Alat Material Handling

\begin{tabular}{|c|c|c|c|c|}
\hline No & Nama Material Handling & $\begin{array}{c}\text { Jarak Perpindahan } \\
(\mathrm{m})\end{array}$ & $\begin{array}{c}\text { OMH } \\
\text { (Rp/meter) }\end{array}$ & $\begin{array}{c}\text { Biaya Perpindahan } \\
\text { MH }\end{array}$ \\
\hline 1 & Forklift 1 & 5760 & 22 & Rp 126.720 \\
\hline 2 & Forklift 2 & 1860 & 22 & Rp $\quad 40.920$ \\
\hline 3 & Forklift 3 & 6664 & 22 & Rp 146.608 \\
\hline 4 & Forklift 4 & 6664 & 22 & Rp $\quad 146.608$ \\
\hline 5 & Forklift 5 & 6664 & 22 & Rp 146.608 \\
\hline 6 & Forklift 6 & 6664 & 22 & $\begin{array}{ll}\text { Rp } & 146.608\end{array}$ \\
\hline
\end{tabular}

Biaya perpindahan sebesar Rp22/meter merupakan biaya yang rendah, melansir dari penelitian yang dilakukan oleh (Sahara, etc) biaya perpindahan material handling dalam perbaikan layout gudang yang mereka lakukan adalah Rp41,03/meter.

\section{b. Biaya Energi}

Biaya energi atau biaya konsumsi energi di fasilitas merupakan biaya yang dihabiskan untuk seluruh mesin atau alat penanganan material yang digunakan sebagai penunjang kegiatan di dalam gudang. Penentuan biaya energi dapat dilakukan dengan ringkasan perhitungan sebagai berikut.

Tabel 11. Perhitungan Biaya Energi

\begin{tabular}{|c|c|c|c|c|c|c|c|c|c|}
\hline No & $\begin{array}{c}\text { Nama } \\
\text { Mesin/Peralatan }\end{array}$ & $\begin{array}{c}\text { Daya } \\
(\mathrm{kWh})\end{array}$ & $\begin{array}{l}\text { Waktu } \\
\text { Proses }\end{array}$ & $\begin{array}{l}\text { Besar } \\
\text { Energi } \\
(\mathrm{kWh})\end{array}$ & Biaya/kWh & $\begin{array}{c}\text { Total Biaya } \\
\text { (Rp/Hari) }\end{array}$ & $\begin{array}{l}\text { Jumlah } \\
\text { (unit) }\end{array}$ & $\begin{array}{c}\text { Biaya } \\
\text { Total/Hari }\end{array}$ & $\begin{array}{c}\text { Biaya } \\
\text { Total/Bulan }\end{array}$ \\
\hline 1 & Mesin Filling & 1.5 & 8 & 12 & $\begin{array}{ll}\mathrm{Rp} & 1.000\end{array}$ & $\begin{array}{ll}\mathrm{Rp} & 12.000\end{array}$ & 1 & $\begin{array}{ll}\mathrm{Rp} & 12.000\end{array}$ & $\begin{array}{ll}\mathrm{Rp} & 264.000\end{array}$ \\
\hline 2 & $\begin{array}{l}\text { Mesin Case } \\
\text { Erector }\end{array}$ & 0.6 & 8 & 4.8 & $\mathrm{Rp} 1.000$ & 4.800 & 1 & 4.800 & Rp $\quad 105.600$ \\
\hline 3 & $\begin{array}{l}\text { Mesin Case } \\
\text { Packer }\end{array}$ & 0.2 & 8 & 1.6 & Rp 1.000 & 1.600 & 1 & 1.600 & 35.200 \\
\hline 4 & Mesin Palletizing & 20 & 8 & 160 & $\operatorname{Rp} 1.000$ & Rp 160.000 & 1 & Rp 160.000 & Rp 3.520.000 \\
\hline 5 & Mesin Wrapping & 1.5 & 8 & 12 & Rp 1.000 & Rp 12.000 & 1 & Rp 12.000 & Rp $\quad 264.000$ \\
\hline 6 & Forklift & 7.5 & 8 & 60 & $\mathrm{Rp} 1.000$ & Rp 60.000 & 6 & Rp 360.000 & Rp 7.920.000 \\
\hline
\end{tabular}

\section{c. Biaya Pekerja Reguler}

Warehouse RWM Logistics berlokasi di dekat Pelabuhan Panjang di kota Bandar Lampung. Untuk menentukan upah pekerja warehouse, perlu diketahui upah minimum di wilayah tersebut. Upah Minimum Kabupaten (UMK) untuk kota Bandar Lampung pada tahun 2019 yang telah ditentukan oleh Gubernur Lampung sebesar Rp 2.445.141 per bulannya. Upah tersebut mengalami kenaikan dari tahun sebelumnya berdasarkan hasil perhitungan yang tercantum dalam Peraturan Pemerintah Nomor 78 Tahun 2015 seperti yang dikutip dalam website alphapay.id [11]. Dengan pertimbangan beban kerja dari pekerja RWM Logistics, maka perusahaan memutuskan upah pekerja per bulan sebesar Rp 2.500.000. Berdasarkan jumlah pekerja regular yang telah ditentukan sebelumnya, dapat dihitung biaya pekerja regular seperti yang dapat dilihat pada tabel di bawah ini. 
Tabel 12. Perhitungan Biaya Pekerja Reguler

\begin{tabular}{ccccc}
\hline No & Nama Pekerjaan & Jumlah Operator & $\begin{array}{c}\text { Upah Pekerja } \\
(\mathrm{Rp} / \text { Bulan) }\end{array}$ & Total Biaya Pekerja \\
\hline 1 & Operator Mesin Filling & 1 & $\mathrm{Rp} 2.500 .000$ & $\mathrm{Rp} 2.500 .000$ \\
2 & Operator Mesin Pengemasan & 1 & $\mathrm{Rp} 2.500 .000$ & $\mathrm{Rp} 2.500 .000$ \\
3 & Operator Mesin Palletizing & 1 & $\mathrm{Rp} 2.500 .000$ & $\mathrm{Rp} 2.500 .000$ \\
4 & Quality Control & 3 & $\mathrm{Rp} 2.500 .000$ & $\mathrm{Rp} 7.500 .000$ \\
5 & Staf Receiving & 1 & $\mathrm{Rp} 2.500 .000$ & $\mathrm{Rp} 2.500 .000$ \\
6 & Staf Shipping & 1 & $\mathrm{Rp} 2.500 .000$ & $\mathrm{Rp} 2.500 .000$ \\
7 & Staf Ground Handling & 3 & $\mathrm{Rp} 2.500 .000$ & $\mathrm{Rp} 7.500 .000$ \\
8 & Operator Forklift & 5 & $\mathrm{Rp} 2.500 .000$ & $\mathrm{Rp} 12.500 .000$ \\
\hline
\end{tabular}

\section{d. Biaya Overtime}

Kebutuhan produksi RWM Logistics dalam satu bulan dipenuhi dengan produksi pada jam regular dan overtime untuk memproduksi safety stock. Safety stock diperlukan untuk menghadapi fluktuasi permintaan yang terjadi satu kali dalam sebulan. Overtime yang telah ditentukan sebelumnya pada Modul 1 Praktikum Perancangan Fasilitas Logistik adalah 2,4 jam. Namun, ada beberapa operator non-mesin yang tidak bekerja secara overtime, yaitu staf receiving, staf shipping, dan staf ground handling. Hal ini dikarenakan ketiga posisi tersebut tidak berhubungan langsung dengan proses yang terjadi di lini produksi. Untuk mengetahui total biaya pekerja adalah sebagai berikut.

Tabel 13. Perhitungan Biaya Overtime

\begin{tabular}{|c|c|c|c|c|c|c|c|}
\hline No & Nama Pekerjaan & $\begin{array}{l}\text { Jumlah } \\
\text { Operator }\end{array}$ & $\begin{array}{c}\text { Jumlah } \\
\text { Jam } \\
\text { Overtime }\end{array}$ & $\begin{array}{r}\mathrm{B} \\
\text { Over }\end{array}$ & $\begin{array}{l}\text { Biaya } \\
\text { time/Jam }\end{array}$ & $\begin{array}{c}\text { Total Biaya } \\
\text { Overtime }\end{array}$ & $\begin{array}{c}\text { Total Biaya } \\
\text { Pekerja }\end{array}$ \\
\hline 1 & $\begin{array}{c}\text { Operator Mesin } \\
\text { Filling }\end{array}$ & 1 & 2.4 & $\mathrm{Rp}$ & 51.136 & Rp 51.136 & Rp 2.551 .136 \\
\hline 2 & $\begin{array}{l}\text { Operator Mesin } \\
\text { Pengemasan }\end{array}$ & 1 & 2.4 & $\mathrm{Rp}$ & 51.136 & Rp 51.136 & Rp 2.551 .136 \\
\hline 3 & $\begin{array}{l}\text { Operator Mesin } \\
\text { Palletizing }\end{array}$ & 1 & 2.4 & $\mathrm{Rp}$ & 51.136 & Rp 51.136 & Rp 2.551 .136 \\
\hline 4 & Quality Control & 3 & 2.4 & $\mathrm{Rp}$ & 51.136 & Rp 153.409 & Rp 7.653 .409 \\
\hline 5 & Staf Receiving & 1 & 0 & & - & - & $\mathrm{Rp} \quad 2.500 .000$ \\
\hline 6 & Staf Shipping & 1 & 0 & & - & - & $\mathrm{Rp} \quad 2.500 .000$ \\
\hline 7 & $\begin{array}{c}\text { Staf Ground } \\
\text { Handling }\end{array}$ & 3 & 0 & & - & - & $\mathrm{Rp} \quad 7.500 .000$ \\
\hline 8 & Operator Forklift & 5 & 2.4 & $\mathrm{Rp}$ & 51.136 & Rp 255.682 & Rp 12.755.682 \\
\hline
\end{tabular}


Hasil rancangan layout keseluruhan PT. RWM Logistics adalah sebagai berikut.

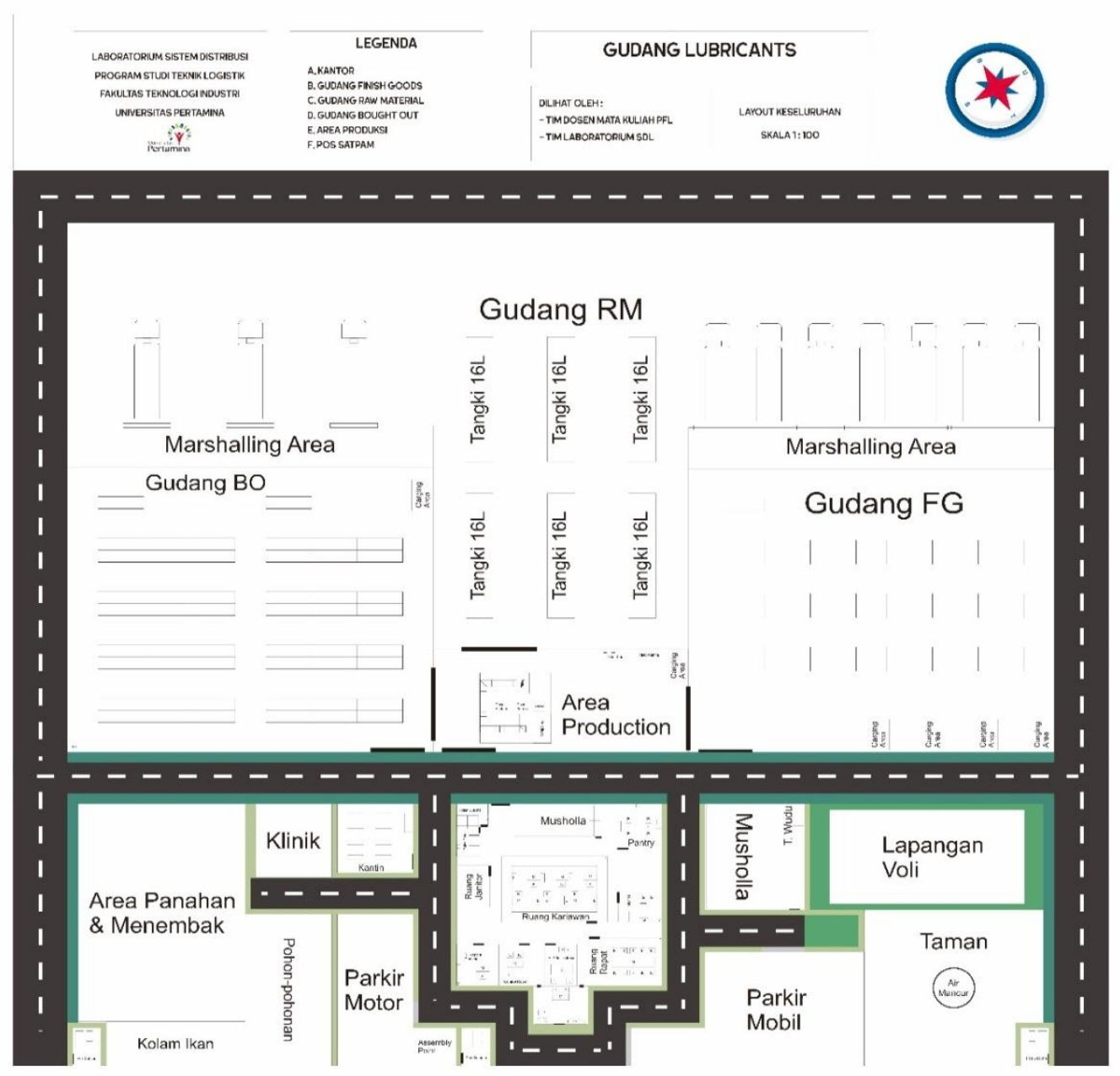

\section{Gambar 3. Layout Hasil Rancangan}

Berdasarkan hasil layout yang telah dirancang terdapat 2 (dua) area yaitu area gudang dan area kantor kedua area tersebut akan dipisahkan oleh jalan. Jika ingin menuju Gudang dan kantor akan memiliki jalan yang berbeda, hal ini dilakukan agar mobil tanki dan mobil kontainer yang akan mengangkut oli tidak mengganggu akses jalan menuju area kantor. Didalam rancangan ini jalur keluar dan masuk kendaraan memiliki akses yang berbeda, tujuannya adalah agar tidak terjadi pertemuan antar truk yang masuk dan keluar sehingga bisa mengurangi resiko kecelakaaan dan mengefisienkan waktu karena akses akan lebih lancar. Pada area gudang, gudang BO dan Gudang finish goods akan dipisahkan oleh area produksi. Layout ini bertujuan untuk mengefesienkan setiap perpindahan dan aliran barang, sehingga jika diterapkan maka tidak akan ada proses bolak-balik, misalnya seperti pada proses pengemasan oli akan dimulai dari barang $\mathrm{BO}$ yang ada digudang $\mathrm{BO}$ akan masuk ke area produksi kemudian akan masuk ke gudang finish goods.

\section{KESIMPULAN}

1. Berdasarkan penelitian yang telah dilakukan, didapatkan beberapa kesimpulan: Fasilitas gudang pelumas mobil akan menggunakan pola $U$ sebagai pola aliran material. Pola $U$ sendiri dinilai dapat memaksimalkan penggunaan docks dan dapat meminimumkan pergerakan barang di dalam fasilitas. 
2. Dikarenakan kapasitas produksi gudang yang cukup besar, maka pemilihan material handling equipment perlu mempertimbangkan luas area yang tersedia. Oleh karena itu, forklift berjenis reach truck dipilih untuk meminimalkan luas aisle yang perlu disediakan.

3. Melalui perhitungan, jumlah lot pemesanan yang dilakukan menggunakan metode EOQ menghasilkan besar lot pemesanan bahan baku sebesar 90.068 liter untuk sekali pesan. Selain itu, besar lot pemesanan untuk barang bought out sebesar 153 unit bulk untuk botol, 4 unit bulk untuk tutup botol, 1 unit bulk gulungan plastik wrap, dan 61 unit bulk untuk kardus.

4. Area di dalam fasilitas gudang PT. RWM Logistics terdiri dari beberapa bagian, yaitu gudang utama, area ruangan kantor, area fasilitas penunjang gudang, area fasilitas penunjang kantor, dan area fasilitas penunjang luar kantor.

5. Kebutuhan pekerja di dalam fasilitas PT. RWM Logistics meliputi 3 orang operator mesin utama, 8 orang operator non-mesin, 6 orang operator alat material handling, dan 18 orang personel kantor.

6. Biaya operasional yang dikeluarkan oleh PT. RWM Logistics selama melaksanakan aktivitas produksi terdiri dari biaya perpindahan, biaya energi, dan biaya tenaga kerja langsung. Total biaya perpindahan yang dikeluarkan untuk keenam forklift yang beroperasi sebesar Rp 754.072 dengan nilai $\mathrm{OMH}$ sebesar Rp 22/meter. Biaya energi yang dikeluarkan meliputi biaya energi untuk seluruh mesin utama dan forklift. total biaya energi yang dikeluarkan sebesar Rp 12.108.800. Untuk biaya tenaga kerja langsung, secara lebih rinci dibagi menjadi biaya pekerja reguler dan biaya overtime. Dalam satu bulan, total biaya pekerja reguler yang dikeluarkan perusahaan sebesar Rp 43.000.000 untuk operator mesin dan operator non-mesin. Sedangkan, biaya overtime yang dikeluarkan sebesar Rp 409.091 untuk total 11 operator mesin dan operator non-mesin.

7. Metode EOQ adalah metode pendekatan yang paling sederhana, metode EOQ cocok digunakan pada sistem ril/nyata dengan beberapa batasan.

\section{DAFTAR PUSTAKA}

BPS Kota Bandar Lampung, “Kota Bandar Lampung dalam Angka 2020,” Bandar Lampung, 2020.

R. S. Russel and B. W. Taylor, Operations Management, 3rd ed. New Jersey: Prentice Hall, 2000.

F. David, Strategic Management: Concepts and Cases. South Carolina: Pearson Education Limited, 2014.

R. Quincy, SWOT Analysis: Raising Capacity of Your Organization. Beijing: Huamin Research Center, 2012.

G. Richards, Warehouse Management: A Complete Guide to Improving Efficiency and Minimizing Costs in the Modern Warehouse. London: Kogan Page, 2004.

S. S. Heragu, Facilities Design, 4th ed. Boca Raton: CRC Press, 2016.

A. Rushton, The Handbook of Logistics \& Distribution Management, 4th ed. London: Kogan Page, 2010.

S. Nahmias and T. L. Olsen, Production and Operations Analysis, 7th ed. Long Grove: Waveland Press, Inc., 2015.

H. Simamora, Manajemen Sumber Daya Manusia, 3rd ed. Yogyakarta: Bagian Penerbitan STIE YPKN, 2004.

G. Dessler, Human Resource Management, 15th ed. Pearson Education Limited, 2017.

F. Zahir, "UMP, UMK, dan UMR Setiap Daerah di Tahun 2019," 2019. https://bills.alterra.id/ump-umk-umr2019/ (accessed Nov. 10, 2019). 